\title{
Phase and compositional evolution of the flooded layer during snow-ice formation on Antarctic sea ice
}

\author{
Ted Maksym, Martin O. Jeffries \\ Geophysical Institute, University of Alaska Fairbanks, 903 Koyukuk Drive, P.O. Box 757320, Fairbanks, AK 99775-7320, U.S.A.
}

\begin{abstract}
A two-dimensional convective transport model has been been developed to investigate the phase and compositional evolution of a flooded slush layer overlying sea ice. The processes governing the solutal and compositional evolution of the flooded layer are investigated in an attempt to explain field observations of salinity and oxygen isotope ratios. Simulations indicate fairly vigorous convective transport in the slush layer, which may lead to the formation of porous channels, depending on permeability. It is found that the salinity and $\delta^{18} \mathrm{O}$ composition of the freezing slush layer is determined primarily by the sea-ice permeability. Simulated salinity and $\delta^{18} \mathrm{O}$ profiles produce varied results, though consistent with observations. The influence of the slush on the salinity and $\delta^{18} \mathrm{O}$ composition of the underlying ice was found to be minimal.
\end{abstract}

\section{INTRODUCTION}

Recent expeditions into the winter Antarctic pack ice have revealed that much of the sea-ice cover is composed of ice with a component of meteoric origin, i.e. snow ice (Allison and Worby, 1994; Eicken and others, 1994; Jeffries and others, 2001). Snow ice is generally understood to be formed through the flooding of the overlying snow cover with brine and/or sea water when the snow load is sufficient to depress the ice surface below sea level, followed by freezing of the resultant snow/brine mixture. This is a ubiquitous circumpolar phenomenon (Allison and Worby, 1994; Eicken and others, 1994; Jeffries and others, 2001), occurring even early during ice development, though snow may have had little time to accumulate (Jeffries and others, 2001). In some regions, such as that stretching from the Ross Sea east to the Antarctic Peninsula, this mode of ice growth may be the dominant means of thermodynamic thickening of the ice cover (Jeffries and others, 2001). Thermodynamic growth of sea ice in this region is, then, governed to a large degree by the cycle of flooding, thinning of the snowpack due to incorporation of the basal layers into the slush, and freezing of a slush layer within the snow/ice system, rather than from the purely liquid phase at the ice bottom. Thus, processes involved in the evolution and thickening of the ice, such as heat transport, fluid flow, salt transport within the ice and rejection into the sea below, and ice microstructural evolution (which control the porosity and ice permeability), may differ substantially from the standard picture of ice growth.

In the Pacific sector of the Southern Ocean, sea-ice cores obtained on several winter cruises revealed that $12-38 \%$ of the total ice mass was composed of snow ice (Jeffries and others, 2001). Unfortunately, identification of snow ice by crystal texture alone is not unambiguous, so recourse to oxygen isotope analysis is required to identify the meteoric component in the ice. Using this technique, standard practice is to identify all samples with $\delta^{18} \mathrm{O}$ values less than zero as snow ice (Lange and others, 1990; Eicken and others, 1994; Jeffries and others, 1998). This leads to calculated snow fractions in the snow-ice samples typically $<13 \%$ (Lange and others, 1990; Jeffries and others, 2001). However, for snow densities that are typically observed (Sturm and others, 1998), snow ice formed by the freezing of a flooded snow layer ought to have entrained snow fractions of about $30-50 \%$. This implies that a large proportion of the water/ ice mixture which is depleted in the heavy isotope (i.e. $\left.\delta^{18} \mathrm{O}<0\right)$ has drained from the slush or snow ice into the underlying ice layers or to the ocean and has been replaced by fresh brine from below during freezing. This has been observed indirectly (although not with respect to isotopic composition) by Fritsen and others (1994) and Lytle and Ackley (1996) during autumn freeze-up in the Weddell Sea, based on inferred nutrient, salt and heat transport. It is this process which casts some doubt on the determinacy of snowice identification: if the isotopic composition is "diffused" along the ice thickness by convection during freeze-up, then snow-ice layers will tend to lose their signature, while underlying ice layers may become depleted in the heavy isotope, leading to a possible ambiguity.

In this paper, we develop a simple model of brine convection during freeze-up of a slush layer to examine the phase, solutal and isotopic evolution of the flooded layer and the underlying sea ice during the freezing process. We investigate three key aspects of this problem: (1) What is the nature of the freezing interface in a flooded layer, i.e. is the thermohaline convection in the slush and ice strong enough to produce a well-defined freezing interface, or is it more diffuse, with phase change occurring across a broader thickness? (2) How much salt is rejected from the flooded layer during freezing, how much of this ends up in the lower portions of the ice, and what is the role of the ice permeability in this process? (3) Can isotopic changes in the ice during freezeup cause substantial redistribution of the heavy isotope?

Salinity and $\delta^{18} \mathrm{O}$ values of individual ice layers sampled during a 1995 winter cruise in the Ross Sea are shown in 


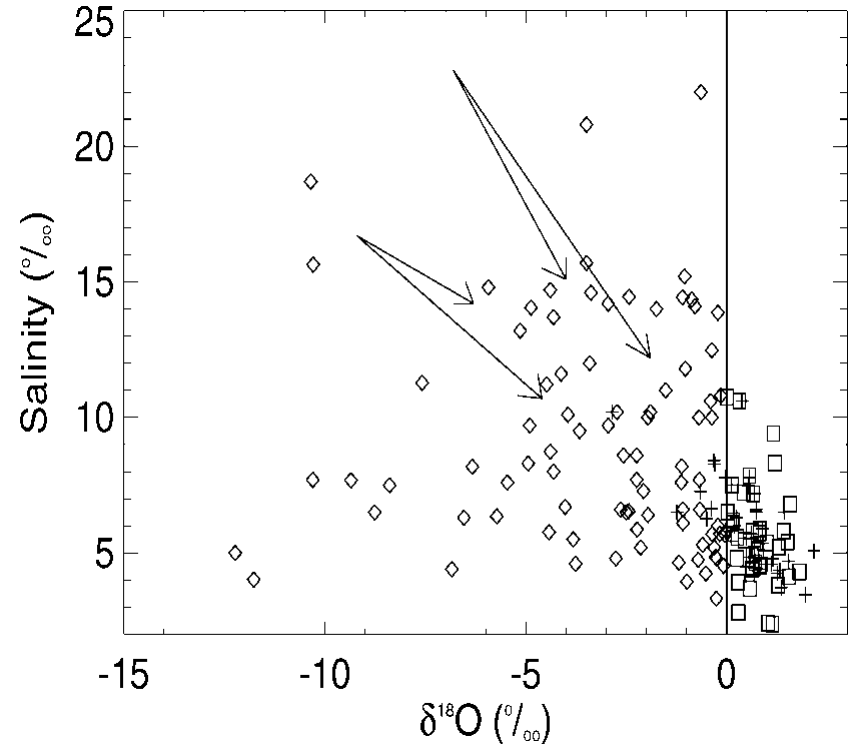

Fig. 1. Scatter plot of ice salinity vs $\delta^{18} O$ for cores obtained during R.V. Nathaniel B. Palmer cruise 95-5 in the Ross Sea during austral winter 1995. The different symbols indicate ice type: $\diamond$, snow ice; +, congelation ice; $\square$, frazil. Snow ice is defined here as granular ice with a negative $\delta^{18} O$ value. The arrows show typical trajectories of simulated composition (see text). For clarity, not all data points are shown.

Figure 1. Observations for other regions, such as the Amundsen and Bellingshausen Seas (Jeffries, unpublished data) and the Weddell Sea (Eicken, 1998), are quite similar. For the 1995 winter Ross Sea samples, the congelation ice generally had a positive isotopic value, with an average of $+0.85 \%$. Similarly, the frazil samples averaged $+0.89 \%$. Several congelation samples had a negative isotopic signature, mostly in the range $-1 \%$ to $0 \%$. These values might be explained by a slight depletion of ${ }^{18} \mathrm{O}$ due to brine convection in the slush penetrating into the underlying ice. These samples were generally well distributed by depth in the core, however. Some of these samples may be of mixed facies.

The snow-ice values covered a wide range, from as low as $-17 \%$ to as high as $0 \%$, with a mean of $-2.8 \%$. Somewhat troubling, with respect to unambiguous identification of snow ice, many of the values were only slightly negative, with $34 \%$ falling between $-1 \%$ and $0 \%$. It is values in this range that we hope to explain with the model. Interestingly, salinity values for the snow-ice layers were highly varied. It is commonly believed that snow-ice layers have a high salinity, due to the large proportion of brine in the original slush. While many of the snow-ice samples do indeed have a high salinity, Figure 1 shows that salinity is not a good indicator of provenance.

\section{MODEL FORMULATION}

The flooded layer and underlying ice is modelled as a porous medium with both convective and diffusive heat and mass transfer and phase change. Generally, the flooded layer is higher in porosity than the ice, so this problem is quite similar to the mushy-layer problem often encountered in alloy solidification (e.g. Worster, 1997). This has been extensively studied theoretically, experimentally and numerically (e.g. Bennon and Incropera, 1987; Tait and Jaupart, 1992; Worster, 1997), and has recently been investigated with respect to the ice/ ocean interfacial layer in growing sea ice (Worster and Wettlaufer, 1997). In some respects, our problem is simpler, in that rather than a mushy layer freezing into a liquid, we have one mushy layer (slush) freezing into another, less porous mushy layer (sea ice), and we can treat both regions with the same set of equations without resorting to complicated volume-averaged equations ( $\mathrm{Ni}$ and Incropera, 1995). Ideally, however, a more robust method should be used, especially when porosities become very high or when drainage tubes are present and inertial effects become important in governing the flow (Schulze and Worster, 1998). For computational convenience, we use a simpler formulation and neglect inertial effects.

The basic equations for conservation of mass, momentum, heat and species transport in a porous medium are given by: conservation of mass,

$$
\frac{\left(\rho_{\mathrm{w}}-\rho_{\mathrm{i}}\right)}{\rho_{\mathrm{w}}} \frac{\partial \phi}{\partial t}+\nabla \cdot \mathbf{u}=0
$$

momentum,

$$
\mathbf{u}=-\frac{K}{\mu}\left(\nabla P+\rho_{\mathrm{w}} \mathbf{g}\right)
$$

heat,

$$
\rho_{\mathrm{m}} C_{\mathrm{m}} \frac{\partial T}{\partial t}+\rho_{\mathrm{w}} C_{\mathrm{w}} \nabla \cdot(\mathbf{u} T)=\nabla \cdot k \nabla T-\rho_{\mathrm{w}} L \frac{\partial \phi}{\partial t}
$$

solute,

$$
\frac{\partial\left(\rho_{\mathrm{w}} \phi S\right)}{\partial t}+\nabla \cdot\left(\mathbf{u} \rho_{\mathrm{w}} S\right)=0
$$

isotopic composition,

$$
\frac{\partial\left(\rho_{\mathrm{w}} \phi \delta_{\mathrm{w}}\right)}{\partial t}+\nabla \cdot\left(\mathbf{u} \rho_{\mathrm{w}} \delta_{\mathrm{w}}\right)=0 .
$$

All symbols are defined in Table 1. Assuming local thermodynamic equilibrium, we have $S=F(T)$, which couples Equations $(1-5)$ by the phase relation. Note that we can neglect diffusion in Equation (4) because the brine

\section{Table 1. Notation}

\begin{tabular}{ll}
\hline $\mathbf{u}$ & Seepage velocity \\
$P$ & Pressure \\
$T$ & Temperature \\
$S$ & Brine salinity \\
$t$ & Time \\
$\phi$ & Porosity (relative brine volume) \\
$\rho$ & Density \\
$C$ & Specific heat \\
$L$ & Latent heat of fusion \\
$k$ & Thermal conductivity \\
$K$ & Permeability \\
$\mathrm{g}$ & Gravitational constant \\
$\mu$ & Brine viscosity \\
$R$ & Isotopic ratio $\left({ }^{18} \mathrm{O} /{ }^{16} \mathrm{O}\right)$ \\
$\delta$ & $\delta^{18} \mathrm{O}=\left(R_{\text {sample }} / R_{\text {std }}\right)-1$ \\
$M$ & Mass $($ ice or brine $)$ \\
$\mathrm{d} m$ & Mass undergoing phase change \\
$\alpha$ & Fractionation coefficient $=1.0029$ \\
$v$ & Mean snow-grain volume \\
$D$ & Diffusivity of salt \\
Subscripts & \\
w & Brine \\
$\mathrm{r}$ & Ice \\
$\mathrm{c}$ & Rayleigh fractionation \\
\hline & Fractionation due to grain coarsening \\
\hline & \\
\hline & \\
\hline &
\end{tabular}


salinity is fixed by the temperature, and the thermal diffusivity is much larger than the solutal diffusivity. Diffusion in Equation (5) is small and has also been neglected. Dispersive effects are not included in Equations (1-5). The method of solution of Equations (1-5) is given in the Appendix.

Equations (1-5) are applied to both the slush and the ice. To avoid steep temperature gradients at the base of the ice due to fixing the temperature of the lower boundary, a thin layer of $100 \%$ porosity is included to roughly simulate the oceanic boundary. This is merely a computational convenience and does not significantly affect the results. Ice-property values, except where noted below, are taken from Cox and Weeks (1988). The density of brine is assumed constant at $1050 \mathrm{~kg} \mathrm{~m}^{-3}$, except in the buoyancy term. Thermal conductivity of the snow is assumed to be $0.3 \mathrm{~W} \mathrm{~m}^{-1} \mathrm{~K}^{-1}$. There is a caveat regarding the application of Equations (1-5) to thermohaline convection in sea ice. To be valid, we must assume that all the pore space is reasonably well connected so that pressure gradients due to density variations vary smoothly. This is probably not the case in general, but here we are concerned with ice that has been warmed by the flooding process, and so brine volumes will be quite high, and therefore the fluid phase should be fairly continuous. The thermal conductivity in the slush is taken as a weighted average of the upper and lower Maxwell bounds (Kaviany, 1995):

$$
\begin{aligned}
k= & \frac{\left[2 k_{\mathrm{i}}+k_{\mathrm{w}}-2 \phi\left(k_{\mathrm{i}}-k_{\mathrm{w}}\right)\right]}{\left[2 k_{\mathrm{i}}+k_{\mathrm{w}}+\phi\left(k_{\mathrm{i}}-k_{\mathrm{w}}\right)\right]} k_{\mathrm{i}}(1-\phi) \\
& +\frac{\left[3 k_{\mathrm{i}}-2 \phi\left(k_{\mathrm{i}}-k_{\mathrm{w}}\right)\right]}{\left[3 k_{\mathrm{w}}+\phi\left(k_{\mathrm{i}}-k_{\mathrm{w}}\right)\right]} k_{\mathrm{w}} \phi .
\end{aligned}
$$

This is valid for both high and low porosities.

The critical parameter in Equations (1-5) is the permeability. Unfortunately, reliable measurements of sea-ice permeability are few and may vary by an order of magnitude or more for the same porosity (Freitag, 1999). Nevertheless, the Kozeny-Carman equation (Kaviany, 1995) with a grainsize of $1 \mathrm{~mm}$ compares reasonably well with measurements by Freitag (1999) for new ice. However, it deviates substantially from his measurements of level Arctic ice at high porosities. The ice permeability used in the model is summarized in Table 2, along with estimates for snow permeability which are used for the slush layer. For very high porosities, the permeability of a circular tube of $5 \mathrm{~mm}$ diameter is used as an approximation of a brine-drainage tube.

\section{ISOTOPIC FRACTIONATION MODEL}

In addition to transport of the heavy isotope of oxygen in the liquid phase due to brine transport, there is an exchange between the liquid and solid phase within a mixture volume. This is due to two main processes: (1) fractionation during freezing, causing heavy-isotope enrichment in the solid phase, with a corresponding decrease in the liquid phase, and (2) isotopic exchange between the phases during snow-grain coarsening in the presence of liquid water. In the first process, the heavy isotope, ${ }^{18} \mathrm{O}$, is preferentially incorporated into the solid phase during freezing. This effect can be described by an equilibrium fractionation ratio, $\alpha$, given by the isotopic ratios in the solid and liquid phases:

$$
\alpha=\frac{R_{\mathrm{i}}}{R_{\mathrm{w}}} .
$$

Eicken (1998) presented a model for this process for cooling sea ice using a Rayleigh fractionation model. Here we use a
Table 2. Snow and ice permeability relations

\begin{tabular}{cll}
\hline \multicolumn{1}{c}{ Porosity } & \multicolumn{1}{c}{ Permeability } & \multicolumn{1}{c}{ Comments } \\
& \multicolumn{1}{c}{$\mathrm{m}^{2}$} & \\
& & $\mathbf{u} \sim 0$ \\
\hline Snow & $1 \times 10^{-15}$ & Kuroiwa (1968) \\
$<0.05$ & $1.2 \times 10^{-13} \mathrm{e}^{18 \phi}$ & Sommerfeld and Rocchio (1993) \\
$0.05-0.28$ & $1.096 \times 10^{-8} \mathrm{e}^{--8.79(1-\phi)]}$ & \\
$0.28-0.86$ & $9.86 \times 10^{-11} \frac{\phi^{3}}{(1-\phi)^{2}}$ & Kozeny-Carman \\
$>0.86$ & & $\mathbf{u} \sim 0$ \\
Ice & $1 \times 10^{-15}$ & Grain-size $=1 \mathrm{~mm}$ \\
$<0.05$ & $5.56 \times 10^{-19} \frac{\phi^{3}}{(1-\phi)^{2}}$ & Tube of diameter 5 mm \\
$>0.05$ & & \\
Maximum $K$ & $7.8125 \times 10^{-7}$ &
\end{tabular}

simplified discrete form. For each time-step, for the freezing of a mass $\mathrm{d} m$ of brine, we may write the isotopic mass balance as

$$
\begin{aligned}
M_{\mathrm{i}} R_{\mathrm{i}} & =\left(M_{\mathrm{i}}-\mathrm{d} m\right) R_{\mathrm{io}}+\alpha \mathrm{d} m R_{\mathrm{w}} \quad \mathrm{d} m>0 \\
M_{\mathrm{w}} R_{\mathrm{w}} & =\left(M_{\mathrm{w}}+\mathrm{d} m\right) R_{\mathrm{wo}}-\alpha \mathrm{d} m R_{\mathrm{w}} .
\end{aligned}
$$

provided $\mathrm{d} m / M_{\mathrm{i}}$ is small. Using

$$
\delta_{\mathrm{i}, \mathrm{w}}=\frac{R_{\mathrm{i}, \mathrm{w}}}{R_{\mathrm{std}}}-1
$$

we obtain

$$
\begin{aligned}
\delta_{\mathrm{i}, \mathrm{r}} & =\delta_{\mathrm{io}}+\frac{\mathrm{d} m}{M_{\mathrm{i}}}\left[\alpha \delta_{\mathrm{wo}}-\delta_{\mathrm{io}}+(\alpha-1)\right] \mathrm{d} m>0 \\
\delta_{\mathrm{w}, \mathrm{r}} & =\delta_{\mathrm{wo}}-\frac{\mathrm{d} m}{M_{\mathrm{w}}}\left[\alpha \delta_{\mathrm{wo}}-\delta_{\mathrm{wo}}+(\alpha-1)\right] .
\end{aligned}
$$

For the case of melting, no fractionation takes place, so we have

$$
\begin{aligned}
\delta_{\mathrm{i}, \mathrm{r}} & =\delta_{\text {io }} & \mathrm{d} m<0 \\
\delta_{\mathrm{w}, \mathrm{r}} & =\delta_{\mathrm{wo}}+\frac{\mathrm{d} m}{M_{\mathrm{w}}}\left(\delta_{\mathrm{wo}}-\delta_{\mathrm{io}}\right) . &
\end{aligned}
$$

The second fractionation process was studied by Raymond and Tusima (1979). Even without a net change in solid fraction, saturated wet snow will undergo grain coarsening in which smaller grains disappear at the expense of larger grains as they round to minimize surface energy. Raymond and Tusima observed that the median particle size for their samples increased linearly with time, at a rate $\mathrm{d} v / \mathrm{d} t=$ $1.23 \times 10^{-6} \mathrm{~mm}^{3} \mathrm{~s}^{-1}$. Nakawo and others (1993) used the results of Raymond and Tusima's experiments to derive an expression for the freezing fraction

$$
\frac{\mathrm{d} m}{M_{\mathrm{i}}}=\beta \ln \left(1+\frac{1}{v_{\mathrm{o}}} \frac{\mathrm{d} v}{\mathrm{~d} t} t\right)
$$

or, in discrete form,

$$
\frac{1}{M_{\mathrm{i}}} \frac{\mathrm{d} m}{\mathrm{~d} t}=\frac{\beta}{v} \frac{\mathrm{d} v}{\mathrm{~d} t}
$$

where the constant $\beta \sim 0.41$ (Nakawo and others, 1993). We can then express the fractionation due to equilibrium grain kinetics as

$$
\frac{\mathrm{d} m}{M_{\mathrm{i}}}=\frac{\beta(\mathrm{d} v / \mathrm{d} t)}{(1+f) v} \mathrm{~d} t,
$$

where $f$ is a scaling factor to account for the slowing of grain 

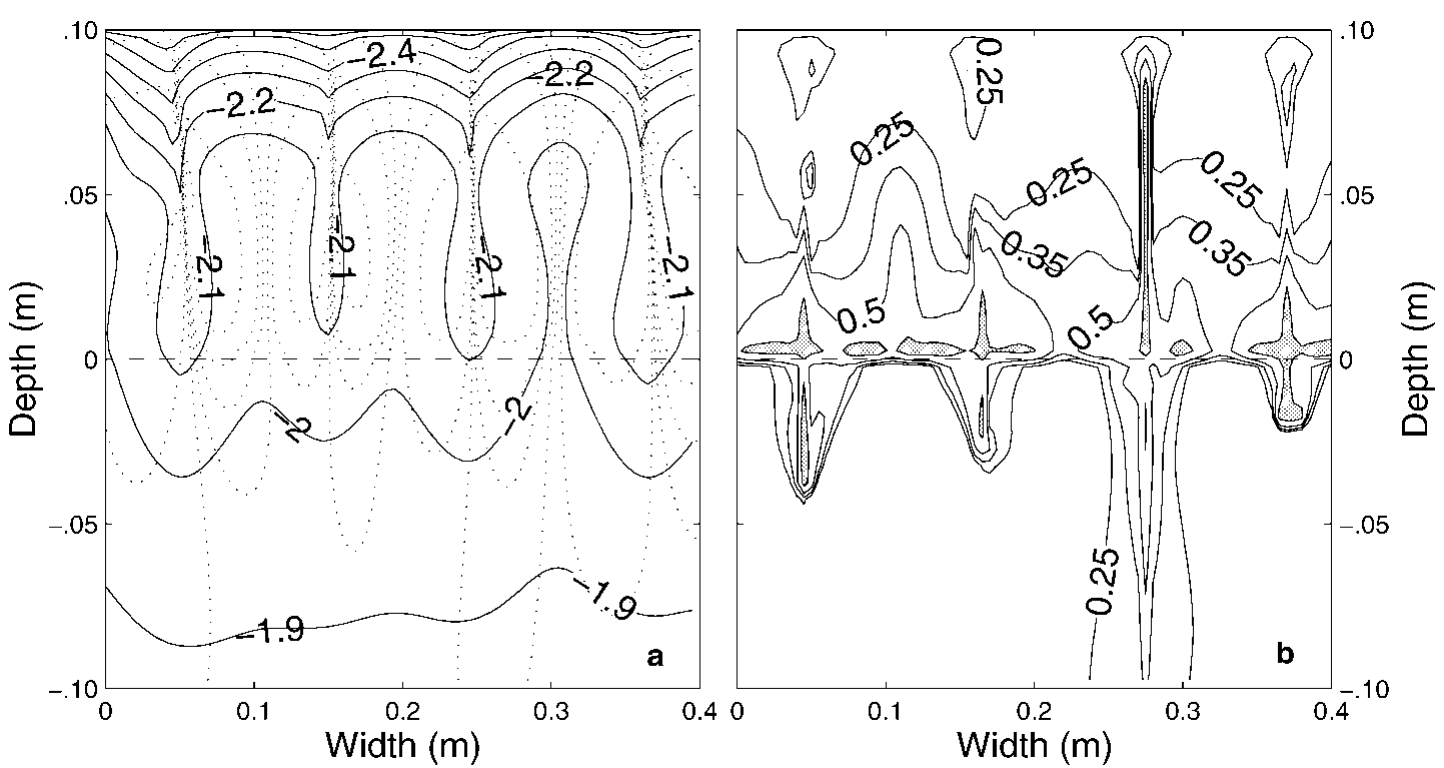

Fig. 2. (a) Convective pattern with streamlines showing salt finger formation for refreezing slush at 1.5 days after flooding. Solid contours indicate temperature $\left({ }^{\circ} \mathrm{C}\right.$ ), and dotted contours represent streamlines. (b) Brine volume (as a fraction of total volume) contour plot after 5 days. Focusing of convection produces highly porous columns (grey areas have brine volumes of $>80 \%$ ) resembling brinedrainage tubes analogous to chimneys formed during the casting of alloys.

growth in the presence of impurities and is given by (Raymond and Tusima, 1979)

$$
f=\left(1+\frac{q_{\mathrm{i}}}{q_{\mathrm{w}}}\right) \frac{k_{\mathrm{w}} T}{\rho_{\mathrm{w}} L D}
$$

where $q_{\mathrm{i}} / q_{\mathrm{w}}$ represents the ratio of the amount of heat transported in the ice to that transported in the liquid during grain coarsening. Since this process will take place in the presence of convective heat transport in the liquid, we assume this term to be zero. For the simulations presented herein, $f \sim 4$, so the rate of grain coarsening is about one-fifth of that of fresh-water slush. Following Equation (10), for fractionation due to grain coarsening, we may write

$$
\begin{gathered}
\delta_{\mathrm{i}, \mathrm{c}}=\delta_{\mathrm{io}}+\frac{\mathrm{d} m}{M_{\mathrm{i}}}\left[\alpha \delta_{\mathrm{wo}}-\delta_{\mathrm{io}}+(\alpha-1)\right] \\
\delta_{\mathrm{w}, \mathrm{c}}=\delta_{\mathrm{wo}}-\frac{\mathrm{d} m}{M_{\mathrm{i}}}\left[\alpha \delta_{\mathrm{wo}}-\delta_{\mathrm{io}}+(\alpha-1)\right] .
\end{gathered}
$$

Nakawo and others (1993) observed less fractionation in their samples than would be predicted by Equations (12) and (16). They attributed this to the presence of a "diffusion layer" of low $\delta^{18} \mathrm{O}$ melt surrounding growing grains during fractionation (e.g. Eicken, 1998). In the presence of convection in the melt, we assume this diffusion layer will be largely absent, and that Equation (16) adequately describes isotopic fractionation due to grain coarsening.

Although we have described fractionation due to equilibrium grain coarsening and bulk-phase change as two separate processes, they certainly are not, in that bulkphase changes will certainly affect the grain-growth rates, and large-scale thermal and solutal gradients will affect the equilibrium processes. However, it is unclear how to couple the two and they are left as separate phenomena to provide a likely upper bound on fractionation rates.

\section{SIMULATIONS}

All model runs were performed for a domain of $1 \mathrm{~m}$ width and $0.5 \mathrm{~m}$ ice thickness. The dry-snow depth was set constant at
$18 \mathrm{~cm}$ with a density of $350 \mathrm{~kg} \mathrm{~m}^{-3}$. Grid spacing was set at $5 \mathrm{~mm}$, and the time-step was set to $600 \mathrm{~s}$. The latter was chosen as a compromise between computational speed and accuracy. Model runs lasted 5-30 days, depending on the rate of freezing. The initial $\delta^{18} \mathrm{O}$ values were set to $-17 \%$ for snow and $-1 \%$ for the infiltrating sea water. These represent typical values for the Pacific Southern Ocean in winter (Jeffries and others, 2001). The initial median snow grain-size was set to $0.5 \mathrm{~mm}$. For the control simulation the surface temperature was set to $-20^{\circ} \mathrm{C}$ and the initial salinity of the ice was set to $8 \%$. At the start of the simulation, it is assumed that the ice has flooded and a slush layer $0.1 \mathrm{~m}$ thick has formed at the base of the snow, and the ice and snow were isothermal at $-1.85^{\circ} \mathrm{C}$, giving an initial ice porosity of $22 \%$ and slush porosity of $62 \%$. This gives initial permeabilities for the ice and slush of $9.7 \times 10^{-11} \mathrm{~m}^{-2}$ and $3.9 \times 10^{-10} \mathrm{~m}^{-2}$, respectively (see Table 2).

During the early stages of the modelled thermohaline convection, plumes of cold, dense brine descend through the slush layer (Fig. 2a). Along these plumes, streamlines tighten, indicating that the flow is being concentrated along the plume as it melts the ice matrix during descent. This increases the permeability along the plume, further concentrating the flow, leading to the formation of narrow columns of high porosity that act as channels for the flow. At the slush/ice interface, the streamlines begin to penetrate into the ice, and extend the channels into the ice (Fig. 2b). The more vigorous salt plumes grow at the expense of their neighbours, as they draw brine from the other plumes. These channels strongly resemble the formation of chimneys which are a common feature in alloy casting (Worster, 1997). Despite the formation of channels, the lower permeability of the ice provides an effective barrier to brine flow, and dense brine remains at the base of the slush layer. A striking feature of this process is the influence of the dynamics in the mushy layer on the formation of channels in the underlying ice. As we shall see, the forcing provided by the highly convective slush may create channels where they would not otherwise form.

The thermodynamic evolution of the system can be seen 


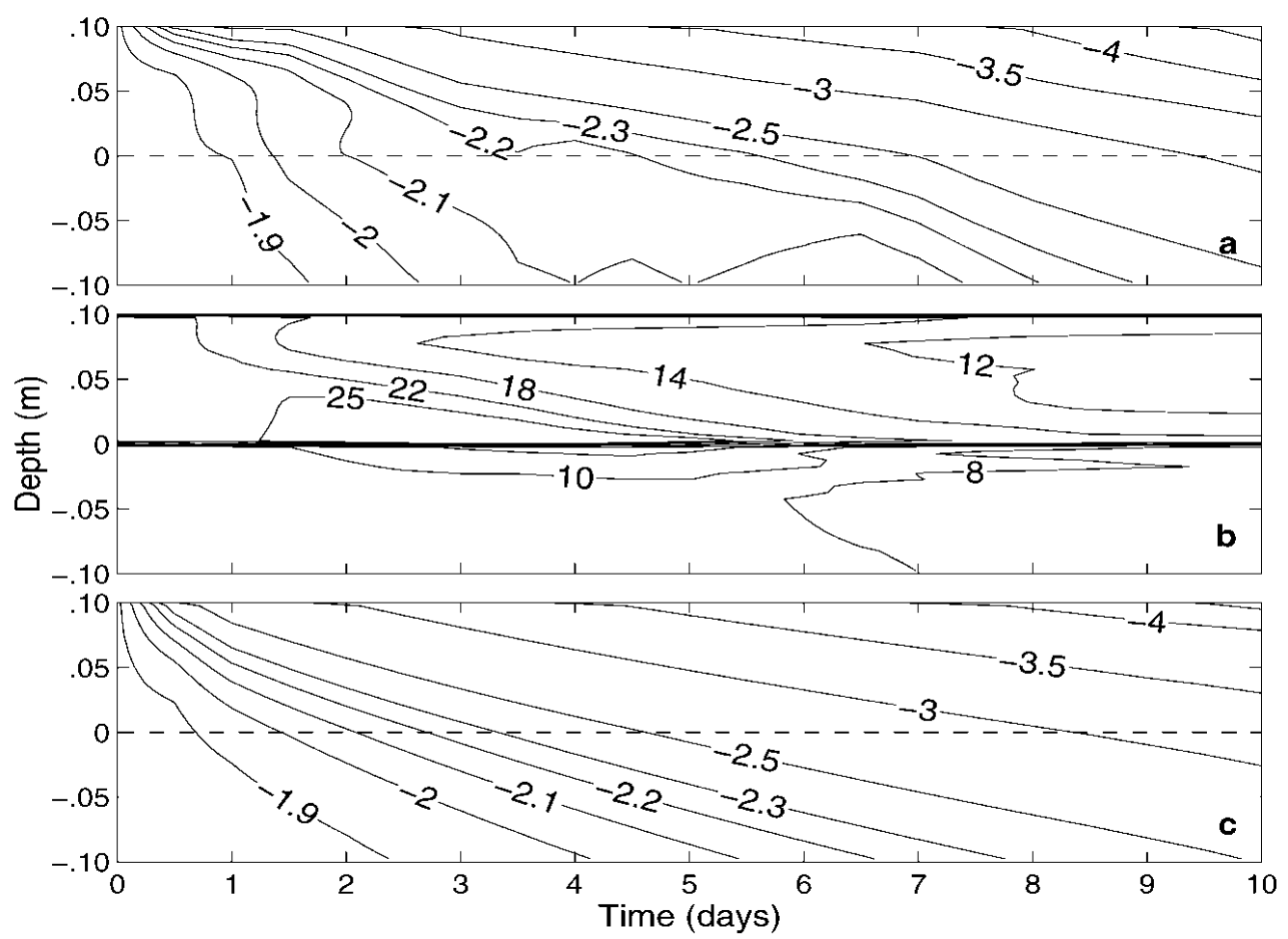

Fig. 3. Time series of temperature $\left({ }^{\circ} C\right.$ ) and salinity (\%o) for a refreezing slush. Zero depth indicates the slush/ice interface. (a) Thermal evolution with convection of a $0.1 \mathrm{~m}$ thick slush layer for a surface temperature of $-20^{\circ} \mathrm{C}(\mathrm{b})$ Salinity profile. (c) Thermal evolution excluding convection. Note that contours are not evenly spaced.

by examining the $-2.1^{\circ} \mathrm{C}$ isotherm of the simulated temperature evolution (Fig. 3a). After an initial cooling of the upper few centimeters, convection begins and the slush layer is quickly cooled and becomes nearly isothermal in the convecting region. In many cases, as shown, the temperature gradient reverses, owing to a cold pulse to the slush/ sea-ice interface, consistent with field observations (Hudier and others, 1995). Dense brine begins to pool at the slush/ice interface, raising the salinity there while lowering it at the top of the slush (Fig. 3b). Initially the convection is confined to the slush only so that there is little heat transfer from the underlying sea ice to the slush. Consequently, the slush cools throughout its entire thickness despite the convecting portion remaining nearly isothermal. Between days 2 and 4 there is a slight increase in the salinity of the upper portion of the sea ice due to entrainment of dense brine as the convection slowly begins to penetrate into the underlying ice. Between days 4 and 10, channels begin to form in the underlying ice, and convection penetrates through to the ocean beneath. The ice warms and rapid drainage of salt from both the slush layer and upper ice continues until the ice permeability drops sufficiently for convection to cease.
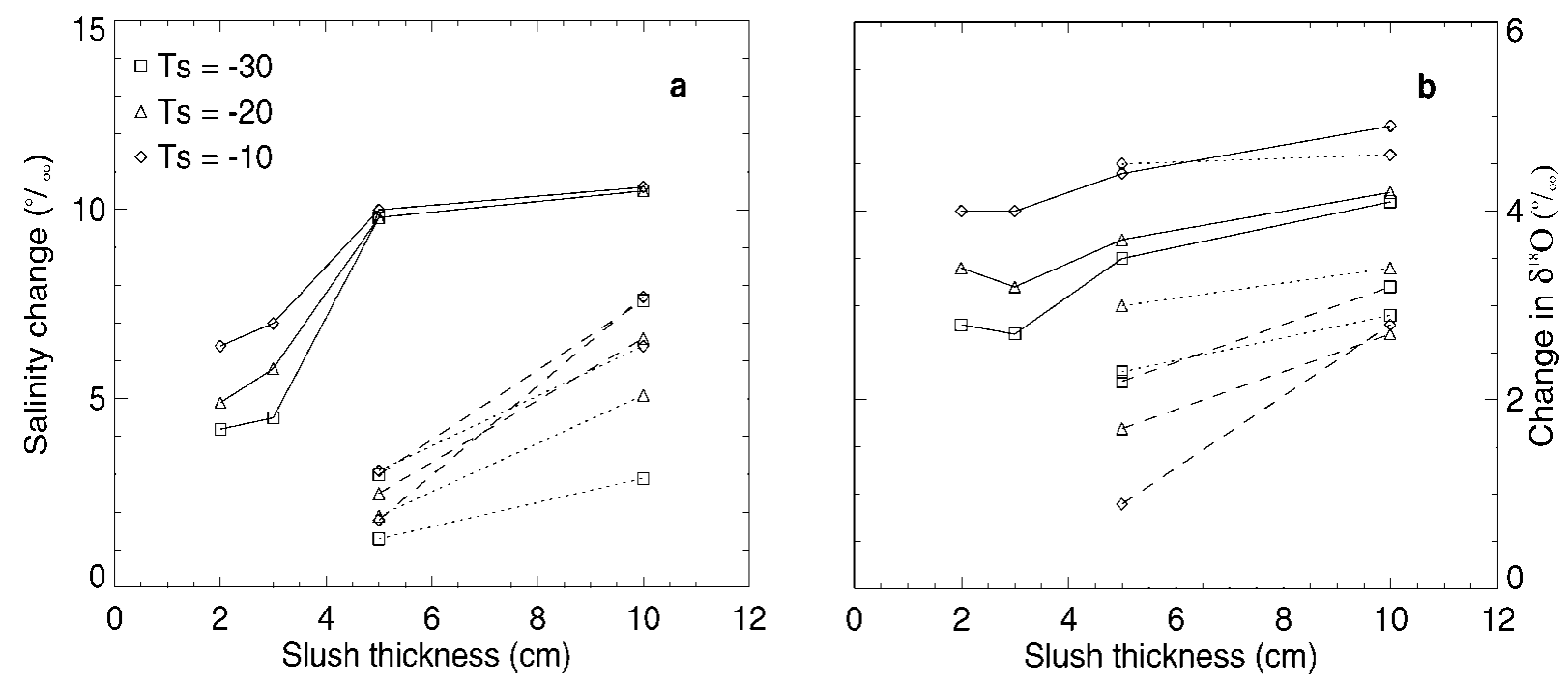

Fig. 4. Salinity decrease (a) and isotopic shift (b) for the slush layer after freezing. Solid lines are for an ice salinity of 8\% and initial snow density of $350 \mathrm{~kg} \mathrm{~m}^{-3}$ ( high ice and slush permeability). Dashed lines are for an ice salinity of 5\%o (low ice permeability), and dotted lines indicate an initial snow density of $500 \mathrm{~kg} \mathrm{~m}^{-3}$ (low slush permeability). The legend indicates the surface temperature ( $\left.T_{\mathrm{S}}\right)$ forcing. 

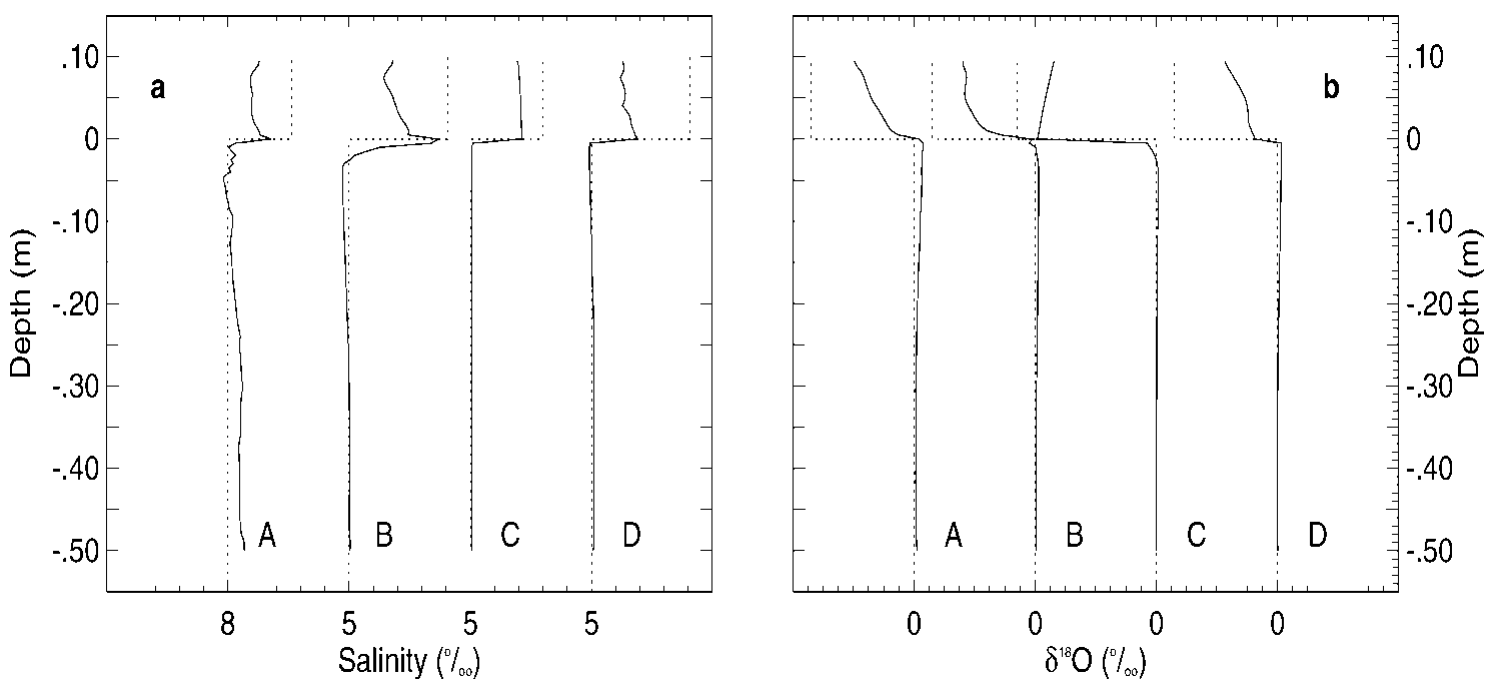

Fig. 5. Salinity ( a) and isotopic (b) profiles for various simulation runs. A, standard simulation; B, initial ice salinity of 5\%o; $C$, initial ice salinity of $5 \%$ and snow density of $500 \mathrm{~kg} \mathrm{~m}^{-3} ; D$, same as simulation B, but with brine drainage tubes present. The dotted lines indicate the initial composition at the beginning of each simulation. The tick interval is 5\%o for salinity and $1 \%$ for $\delta^{18} \mathrm{O}$.

Comparing the thermal evolution with convection to that without convection (Fig. 3c) shows that although the advance of the isotherms is slowed during convective events, there is only a moderate difference in the temperature profiles for the convecting and non-convecting cases. Generally, the convection provides a heat flux of only $2-4 \mathrm{~W} \mathrm{~m}^{-2}$ to the slush layer from below, while the conductive heat flux through the snow was approximately $25 \mathrm{~W} \mathrm{~m}^{-2}$. The effect of convective heat flux to the slush is compensated by the increase in thermal conductivity due to brine drainage so that after 10 days the temperature profiles of the convecting and non-convecting case match closely.

In order to examine the effect of permeability on the amount of salt rejected from the slush layer during freeze-up, we examine three main scenarios: one with high permeability in both the slush and ice, a second with high permeability in the ice only, and a third with high permeability in the slush only (Fig. 4a). For each group, there is only a modest dependence of brine rejection on forcing temperature, perhaps reflecting the competing effects of temperature on the amplitude of convection and permeability, which decreases with decreasing temperature. Primarily, however, the drainage is governed by the ice permeability. Although the amount of salt drained is smaller for those simulations with higher initial snow density (i.e. lower slush permeability), the final slush salinity is only slightly below that of the higher-permeability case. The difference in salinity between the two cases is primarily a result of a $6 \%$ difference in initial slush salinity. In contrast, for lower ice permeability, drainage is substantially reduced. The results for variation of the isotopic composition of the frozen slush layer (Fig. 4b) show less distinction, with increases of about $2-5 \%$, representing final compositions of $-1.9 \%$ o to $-6.9 \%$. The increase in the $\delta^{18} \mathrm{O}$ values is most dependent on the thermal driving force, since grain coarsening can progress further if the rate of freezing is reduced. Trajectories of the salinity and isotopic composition for typical results are plotted as arrows in Figure 1. The model can produce substantial shifts in the composition of the slush and demonstrate final salinity $-\delta^{18} \mathrm{O}$ relationships within the observed range of values, although generally within the higher range of salinities.

An important characteristic of the slush/sea-ice system is that it often consists of a highly saline layer immediately above a less porous layer of an often much lower salinity. It has been suggested (Maksym and Jeffries, 2000) that brine drainage from the freezing slush may contribute to the salination of the upper layers of the ice, thereby increasing its porosity. To demonstrate the role of permeability in the drainage of salt from the slush and possible salination of the ice, several salinity profiles after a 10 day period are shown in Figure 5a. Curve A is the simulated profile for the same model run as in Figure 3. Again, we note that the high permeability in both the slush and ice leads to efficient drainage of both regions. Once the convection has extended into the upper part of the ice, the salinity there initially increased due to a salt flux from the slush. However, once channels penetrated to the ice/ocean interface, this excess salt drained rapidly, and there was little net change in the ice salinity. For curve $\mathrm{B}$, the ice salinity is set to $5 \%$ rather than $8 \%$. This reduces the ice permeability, providing an effective barrier to drainage, and, although the upper portions of the slush drained quite effectively, this salt was trapped at the slush/ice interface. Convection in the ice still occurred and drainage channels formed, but sufficiently slowly that a modest increase in salinity (about 1\%o) occurred in the upper part of the ice due to salination from the freezing slush. After 10 days, however, this salination slowed and slow drainage produced a net reduction in ice salinity. The simulation in curve $\mathrm{C}$ was the same as for $\mathrm{B}$, except that the initial snow density in the slush was set to $500 \mathrm{~kg} \mathrm{~m}^{-3}$, to reflect possible settling of snow during flooding (Eicken and others, 1995). Because of the relatively weak convection in the slush, channels did not form and convection into the underlying ice served to increase the ice salinity. The salinity of the slush layer remained quite high after freezing. Note the difference between runs $\mathrm{B}$ and $\mathrm{C}$ : no channels formed during run $\mathrm{C}$, but in run $\mathrm{B}$ the focusing of the flow in the convecting slush allowed the initiation of drainage channels in the underlying ice, eventually allowing for partial drainage of the salt from the slush layer.

In real sea ice, brine-drainage channels may be present before flooding (indeed, that may facilitate the flooding in the first place). Therefore, we present a simulation with channels placed a priori at $0.5 \mathrm{~m}$ intervals, shown in curve $\mathrm{D}$. This demonstrates the importance of the spatial geometry of the 
ice permeability in governing the brine redistribution. Brine drainage from the slush layer was very efficient, without a substantial increase or reduction of the salinity of the bulk ice.

Isotopic profiles show the greatest increase in $\delta^{18} \mathrm{O}$ for simulations A and D (Fig. 5b). Isotopic ratios are increased throughout the slush thickness, but quite substantially near the ice interface, with values as high as $-1 \%$. In curve $\mathrm{C}$, note that there is some isotopic depletion in the upper regions of the ice due to slow convective transport into the ice, although at most this depletion amounts to a shift in isotopic signature of $0.6 \%$.

\section{DISGUSSION}

The ability of a slushy layer to efficiently desalinate is primarily dependent on the existence of drainage channels; either existing channels, or those created through the flow-focusing convective process. For the snow permeabilities used, the Rayleigh number for the flooded layer is above critical. The presence of convection does not guarantee the formation of channels, for, if the flow is slow enough, thermal diffusion will reduce the strong porosity gradients, and the plumes may not focus sufficiently. In practice, this is unlikely, as the increase in snow-grain coarseness with wetting will most likely increase the permeability above the values used in the present simulations. Observed snow permeabilities for coarsegrained snow are much higher than for fine-grained snow (Kuroiwa, 1968; Shimizu, 1970).

The simulated convection acts much like that described by Worster and Wettlaufer (1997) at the ice/ocean interface of growing sea ice. Convection in the slush acts somewhat like a boundary-layer mode, with salt redistributed within the slush, but confined within this layer until convection is initiated in the underlying sea ice. If convection is strong enough in the slush layer, it can penetrate into the ice, especially if the flow is focused into drainage channels, and thus can force convection in ice that would otherwise not convect on its own. This allows the slush layer, in effect, to create drainage channels of its own that aid in the reduction of the layer's salinity.

An increase in the $\delta^{18} \mathrm{O}$ values of the slush layer is also aided by the presence/formation of channels, but to a lesser degree. The shift in isotopic composition in the simulations is largely due to metamorphic changes within the layer itself, and the convective transport of the liquid fraction. Model results indicate a shift in isotopic fraction of several parts per thousand. In the extreme case, if a slow refreezing is allowed to maximize the effects of metamorphic changes, bulk isotopic values can be raised to about $-1.9 \%$, although local changes within the slush layer (e.g. at the slush/sea-ice interface) can be larger. Since the transport of the liquid fraction is primarily through rapidly draining channels, negative shifts of the isotopic composition of the underlying ice layers are minimal, perhaps no more than 1\%o. Although such shifts occur frequently during the freezing of the slush, the fractionation that occurs once the sea ice begins to cool increases the simulated $\delta^{18} \mathrm{O}$ values, effectively cancelling the previous reduction.

Results described herein are highly sensitive to the underlying ice permeability. A reduction in permeability of a factor of five (based on salinity differences) can produce a similar contrast in the amount of salt drained (Fig. 4). Unfortunately, the ice permeabilities can vary by more than an order of magnitude (Freitag, 1999), so predictive determinations of the salinity and isotopic profiles in floodfreeze cycles are presently not possible.

Although the formation of brine channels may be consistent with observations (Worster, 1997), there are several limitations in the model which need to be addressed. It should be noted that the resolution of the model does not allow a proper treatment of the channel dynamics, as they tend to be only one grid spacing in width, whereas actual drainage tubes may exhibit complex behavior (Niedrauer and Martin, 1979). In the slush, these channels may be affected by motion of the snow grains. The rounding of snow grains during coarsening will tend to reduce the structural strength of the snowpack so that grains may settle into voids, thus partially impeding the development of highly porous channels. At low brine volumes, discontinuities in the pore space may cause flow variations on the order of the scale of interest, and effects such as hydrodynamic dispersion may become important. There will likely be substantial variations in permeability on a small scale due to microstructural variations or, in the case of congelation ice, anisotropic permeability, which may have important effects on the fluid flow. Further laboratory and modelling work is needed to investigate the behavior of thermohaline convection in sea ice.

\section{CONGLUSION}

We may note some general behavior of the freezing-slush/ice system. Thermohaline convection during freezing of the slush layer may be fairly effective at solute transport, but it is generally not vigorous enough to create a well-defined freezing front, and cooling can occur through the entire slush layer before it freezes. The thermal evolution of the slush/ice system can be adequately treated by simple thermal diffusion provided a rough estimate can be made of the brine rejected. Brine drainage due to convection is primarily dependent on the permeability of the underlying ice, although if the convection in the slush layer is vigorous enough, it may penetrate into an otherwise impermeable ice layer and initiate the formation of drainage channels. Salt that has drained from the slush passes through channels that carry the salt effectively to the water column. Salination of the sea ice by the overlying slush may be minimal. These observations are contrary to the suggestion that this convection can contribute to maintaining high porosity in the upper part of the ice (Maksym and Jeffries, 2000). Simulated brine drainage reduced the salinity of the slush layer by as much as half, to as low as $10 \%$ in a few days. If the convection can penetrate through the ice layer, slush salinities fall to $10-13 \%$ before convection ceases, though this range is a function of the prescribed snow permeability.

The isotopic composition of the slush layer was raised by as much as $4-5 \%$ during freezing, to as high as $-1.9 \%$. This can only account for about $50 \%$ of the $\delta^{18} \mathrm{O}$ values reported for ice believed to be formed by the flooding and freezing process. However, since many of the simulated $\delta^{18} \mathrm{O}$ values are due to ${ }^{18} \mathrm{O}$ depletion in the interstitial liquid, it is conceivable that subsequent flooding and refreezing events and brine-drainage processes over the long term could displace this brine and continue to reduce the salinity and raise the $\delta^{18} \mathrm{O}$ value so that the full range of observed values (Fig. 1) could result. If such longer-term brine-transport 
processes could cause post-genetic isotopic shifts in the snow ice of $1-2 \%$, then it may be possible to explain the full range of negative $\delta^{18} \mathrm{O}$ values observed by the flood-freeze process. As the compositional shift in the underlying ice was minimal, we do not expect isotopic shifts in congelation or frazil ice due to compositional convection to be large, and so the number of "false positives" when using isotopes to identify snow ice may be minimal. The model simulations suggest that the identification of any granular ice with a negative $\delta^{18} \mathrm{O}$ value as snow ice may be a reasonable criterion for determining the amount of snow ice and its contribution to the mass balance of the ice cover.

\section{ACKNOWLEDGEMENTS}

This research was supported by U.S. National Science Foundation grant OPP-9316767, and by a grant of highperformance computing time from the Arctic Region Supercomputing Center.

\section{REFERENCES}

Allison, I. and A. Worby. 1994. Seasonal changes of sea-ice characteristics off East Antarctica. Ann. Glaciol., 20, 195-201.

Bennon, W. D. and F. P. Incropera. 1987. A continuum model for momentum, heat and species transport in binary solid-liquid phase change systems. II. Application to solidification in a rectangular cavity. Int. F. Heat Mass Transfer., 30(10), 2171-2187.

Cox, G. F. N. and W. F. Weeks. 1988. Numerical simulations of the profile properties of undeformed first-year sea ice during the growth season. 7. Geophys. Res., $93(\mathrm{C10}), 12,449-12,460$.

Eicken, H. 1998. Deriving modes and rates of ice growth in the Weddell Sea from microstructural, salinity and stable-isotope data. In Jeffries, M. O., ed. Antarctic sea ice: physical processes, interactions and variability. Washington, DC, American Geophysical Union, 89-122. (Antarctic Research Series 74.)

Eicken, H., M. A. Lange, H.-W. Hubberten and P. Wadhams. 1994. Characteristics and distribution patterns of snow and meteoric ice in the Weddell Sea and their contribution to the mass balance of sea ice. Ann. Geophysicae, 12(1), 80-93.

Eicken, H., H. Fischer and P. Lemke. 1995. Effects of the snow cover on Antarctic sea ice and potential modulation of its response to climate change. Ann. Glaciol., 21, 369-376.

Freitag, J. 1999. Untersuchungen zur Hydrologie des arktischen Meereises Konsequenzen für den kleinskaligen Stofftransport. Ber. Polarforsch./Rep. Pol. Res. 325.

Fritsen, C. H., V. I. Lytle, S. F. Ackley and C.W. Sullivan. 1994. Autumn bloom of Antarctic pack-ice algae. Science, 266(5186), 782-784.

Hudier, E. J.-J., R. G. Ingram and K. Shirasawa. 1995. Upward flushing of sea water through first year sea ice. Atmosphere-Ocean, 33(3), 569-580.

Jeffries, M. O., S. Li, R. A. Jaña, H. R. Krouse and B. Hurst-Cushing. 1998. Late winter first-year ice floe thickness variability, seawater flooding and snow-ice formation in the Amundsen and Ross Seas. In Jeffries, M. O., ed. Antarctic sea ice: physical processes, interactions and variability. Washington, DC, American Geophysical Union, 69-87. (Antarctic Research Series 74.)

Jeffries, M. O., H. R. Krouse, B. Hurst-Cushing and T. Maksym. 2001. Snow-ice accretion and snow-cover depletion on Antarctic first-year sea-ice floes. Ann. Glaciol., 33 (see paper in this volume).

Kaviany, M. 1995. Principles of heat transfer in porous media. Second edition. New York, etc., Springer-Verlag.

Kuroiwa, D. 1968. Liquid permeability of snow. International Association of Scientific Hydrology Publication 79 (General Assembly of Bern 1967-Snow and Ice), 380-391.

Lange, M. A., P. Schlosser, S. F. Ackley, P. Wadhams and G. S. Dieckmann. 1990. ${ }^{18} \mathrm{O}$ concentrations in sea ice of the Weddell Sea, Antarctica. 7 . Glaciol., 36(124), 315-323.

Lytle, V. I. and S. F. Ackley. 1996. Heat flux through sea ice in the western Weddell Sea: convective and conductive transfer processes. 7. Geophys. Res., 101(C4), 8853-8868.

Maksym, T. and M. O. Jeffries. 2000. A one-dimensional percolation model of flooding and snow-ice formation on Antarctica sea ice. 7. Geophys. Res., $\mathbf{1 0 5}$ (C11), 26,313-26,331.

Nakawo, M., S. Chiba, H. Satake and S. Kinouchi. 1993. Isotopic fractionation during grain coarsening of wet snow. Ann. Glaciol., 18, 129-134.

$\mathrm{Ni}$, J. and F. P. Incropera. 1995. Extension of the continuum model for transport phenomena occurring during metal alloy solidification. I.
The conservation equations. Int. 7. Heat Mass Transfer., 38(7), 1271-1284. Niedrauer, T. M. and S. Martin. 1979. An experimental study of brine drainage and convection in young sea ice. 7. Geophys. Res., 84(C3), 1176-1186.

Raymond, C. F. and K. Tusima. 1979. Grain coarsening of water-saturated snow. 7. Glaciol., 22(86), 83-105.

Schulze, T. P. and M. G. Worster. 1998. A numerical investigation of steady convection in mushy layers during the directional solidification of binary alloys. F. Fluid Mech., 356, 199-220.

Shimizu, H. 1970. Air permeability of deposited snow. Contrib. Inst. Low Temp. Sci., Ser. A 22

Sommerfeld, R. A. and J. E. Rocchio. 1993. Permeability measurements on new and equitemperature snow. Water Resour. Res., 29(8), 2485-2490.

Sturm, M., K. Morris and R. Massom. 1998. The winter snow cover of the West Antarctic pack ice: its spatial and temporal variability. In Jeffries, M. O., ed. Antarctic sea ice: physical processes, interactions and variability. Washington, DC, American Geophysical Union, 1-18. (Antarctic Research Series 74.)

Tait, S. and C. Jaupart. 1992. Compositional convection in a reactive crystalline mush and melt differentiation. 7. Geophys. Res., 97(B5), 6735-6756.

Worster, M. G. 1997. Convection in mushy layers. Annu. Rev. Fluid Mech., 29, 91-122.

Worster, M. G. and J. S. Wettlaufer. 1997. Natural convection, solute trapping, and channel formation during solidification of saltwater. 7. Phys. Chem., Ser. B, $101(32), 6132-6136$.

\section{APPENDIX}

To solve Equations (1-5), we first decompose $\mathbf{u}$ into solenoidal and irrotational constituents,

$$
\mathbf{u}=\nabla \times \psi+\nabla \zeta .
$$

The second term on the righthand side of Equation (Al) represents brine flow due to volumetric expansion of water during freezing. Note that in two dimensions the stream function, $\psi$, has only one component, perpendicular to the velocity. Taking the curl of Equation (2) to eliminate the pressure term, we obtain

$$
\nabla \times \frac{1}{K} \nabla \times \psi=g \frac{\partial \rho}{\partial x} .
$$

This is strictly correct only for constant permeability, but typically $\nabla \times \psi \gg \nabla \zeta$, so we neglect the influence of the smaller term on the Darcian flow. We can then express Equation (1) as

$$
\nabla \cdot \mathbf{u}=\nabla^{2} \zeta=\frac{\left(\rho_{\mathrm{i}}-\rho_{\mathrm{w}}\right)}{\rho_{\mathrm{w}}} \frac{\partial \phi}{\partial t} .
$$

The energy equation (3) can be simplified by noting that over the small range of temperatures of interest here, $S \sim T$. Then, combining Equations (3) and (4), we obtain

$$
\left(\rho_{\mathrm{m}} C_{\mathrm{m}}-L \frac{\rho_{\mathrm{w}} \phi}{T}\right) \frac{\partial T}{\partial t}+\rho_{\mathrm{w}}\left(C_{\mathrm{w}}-\frac{L}{T}\right) \nabla \cdot(\mathbf{u} T)=\nabla \cdot k \nabla T .
$$

To solve the modified set of Equations (4) and (5) (A1-A4), we first solve for the stream function, $\psi$, from Equation (A2), calculate the velocities assuming $\partial \phi / \partial t=0$, then solve Equations (4) and (A3). Material properties are updated to determine $\partial \phi / \partial t$, and Equation (A3) is solved. Using the total velocity, the final solution is calculated using Equations (4), (5) and (A4), and all material properties are recalculated. Only one iteration is performed for computational efficiency.

Equations (4), (5) and (A4) are solved using an implicit alternating-direction technique, while Equations (A2) and (A3) are solved by an iterative under-relaxation Poisson solver. The vertical velocity at the upper boundary is set to zero, and the horizontal velocity is set to zero at the open lower boundary. Lateral boundaries are periodic. 